\title{
The Biological Basis of Performativity of Identity - Linking Scientific Evidence to Social Theory
}

\author{
Godwin R. Constantine ${ }^{1}$ \\ Eastern University of Sri Lanka
}

\begin{abstract}
Identity is the essence of performance and performance is the essence of identity. Without identity our performance does not assume any cultural significance. Our relative identity allows our performance to be located in the socio-cultural space. Our identity forms the foundation for the discursive significance of our performance. However, our identity is not unique, it is established by performing a pre-existing script. The biological basis of identity can be understood by applying learning theories and by analyzing how these leant behavior is embedded in our neuronal network in the brain and how these behavior patterns are controlled by psychological factors to result in the identity we observe. Recent developments in the fields of neuroscience and functional neuro imaging have enabled us to study objectively the process of neural mechanisms and map areas of brain that are involved in learning various behavior patterns. These neuronal networks and the neuro transmitters play a key role in memory and behavior of animals. Aby studying the particular pattern of behavior and the brain area that mediates that behavior it will be possible to determine neuronal networks that control core identity characteristics and that control other less important characteristics. With the emergence of studies in neuroplasticity the possibility of relearning behaviors through new neuronal pathways may open new avenues to treat conditions that affect identity. Understanding the biological basis of identity will lead to widening of research area and better understanding of the concept. Keywords: Identity, Performativity, Performance, Neuronal network, functional neuroimaging, biology of identity.
\end{abstract}

\section{Introduction}

Identity is a keyword in the contemporary socio-cultural discourse. Identity is what give meaning to our existence. Our social interactions are relative to our socio-cultural identity. Identity has been a topic of much interest in many fields. However, it has remained a topic of interest mainly in the fields of social sciences and humanities.

In the post-Human Genomic Project period many genetic studies have focused on genetic basis of ethnic and race identity. Many genetic studies have been carried out in various parts of the world find similarities and differences in genetic constitution of ethnic groups. These studies and behavioral genetic studies have to a large extent showed that these differences and similarities can be found in biological body systems and morphological characteristics (Bloche, 2004; Mountain \& Risch, 2004). Recent development in the field of neuroscience could form the basis for understanding the possible biological mechanisms involved in identity formation. Along with these neural mechanisms learning theories and psychological mechanisms can provide the frame work for learning, retaining and performing various behavioral patterns of identity.

The identity characteristics can be variously learnt, ingrained in the neuronal circuits and stored in the mind resulting in some characteristics functioning as core characteristics and other as modifiable characteristics. This model will help us to understand the development and control of identity characteristics under the influence of factors within and without.

\section{Sociology of Identity}

In ancient times where the society was stable, changes were gradual, people were born into in Lacanian terms "a world of assigned symbolic order made of linguistic codes" (Bracher, 1994). In the contemporary world the symbolic order of our context changes rapidly due to development and displacement, we are forced to select or adopt identities in the context we perform. The late modern social theorists have taken these changes in proposing a new sociological perspective on identity in late modern period (Beck, 1992; Damgaci \& Aydin, 2013; Giddens, 1991; Tarman, 2017; Yiğit, \& Tarman, 2016).

${ }^{1}$ E-mail: constantinegr@ clinmed.cmb.ac.lk 
Identity is what segregates people and embed pride and prejudices in the minds of people which results in conflicts and leads to wars.

At the outset it is important to clarify what I mean by identity in the context of my paper. In the sociology literature self-concept and identity are often used interchangeably. Self-concept and identity are closely linked concepts. Self-concept is a mental image that exists only in one person's mind, whereas identity is socially applicable dimension of self. According to Baumeister self-concept is: "The individual's belief about himself or herself, including the person's attributes and who and what the self is" (1999, p. 13). There is no singular identity for a person. It is generally agreed that multiple identities exist (Owens, Robinson \& Smith-Lovin, 2010).

Identity has been a contentious issue in many fields over the years. The main focus of this paper will be on the socio-cultural/ethnic identity. Initially we shall deal with some theoretical aspects of identity, psychological theories of learning, relevance of neuroscience to "identity learning" and the possible role of mind in identity formation. This can be used as the ground work to understand how empirical foundation can form the basis for socio-cultural discourse.

As a working definition Identity can be regarded as a unifying word that denotes set of characteristics like qualities, beliefs, and expressions that by which a person or a group is definitively recognizable. Identity is a mental construct which is molded by the contexts in which it develops and influences action.

Identity is not totally stable it has components which are context sensitive (Kiang, 2014). Research has shown that identity can be influenced by factors that matters to others in a community of an organization, factors that promote individuals' advancement and by things that are relevant and important at that time (Ramanadan, 2014).

Identity formation segregates people into groups. When we identify with a group we exhibit the characteristics of the other in-group members. Identity characteristics and identity functions can be analysed based on similarities with other in-group members (Brewer, 2001; Ugurlu, 2014) and also by analyzing the distinctions between in-group and out-group members (Stapel \& Koomen, 2001). Identity depends on groups that we identify with and it is likely to change with the situation and duration we are embedded in it (Brewer, 1991; Oyserman, 2007).

To understand the dynamic nature of identity we need to focus on socio- psychological foundation of identity. The sociological basis of identity formation can be understood by analyzing two processes involved in social learning namely social cognition and symbolic interaction. Social cognition is a process by which an individual understands and make sense of the environment by trying to understand and explain how the thoughts, feelings, and behavior of individuals are by the presence of others. (Frith, 2008). The organized sets of information on identity which are the cognitive schema forms the mental mapping for social cognition. This schema can be related to self - self schema or it can relate to the group - group schemas which involve sets of information on groups we identify with such as race, religion, social strata etc. (Byker \& Marquardt, 2016; Tajfel \&Turner, 2004).

Based on this schema individuals define their identities in two dimensions, social and personal identities. Social identity enhances self-image and the individual is likely to associate with groups which positively contributes to self-esteem and discriminate against outgroups. Hence personal identity and social identity are interrelated and interdependent (Swann, Gómez, Seyle, Morales, \& Huici, 2009).

Symbolic interaction is the other major framework of sociological theory that could be used to understand the development of identity. This perspective relies on the symbolic meaning that people develop and rely upon in the process of social interaction. This perspective sees the self as culmination of reflected appraisals in social interactions. People interact with objects, people and behaviors in society. These interactions create a symbolic meaning to self. In this approach we can identify two aspects of identity. One depends on the role one plays in the social structure like father, manager, brother etc. (Stryker, 1980). The other is the identity created through the process of self-presentation (Goffman, 1959).

Both social cognition and symbolic interaction theories emphasizes that the identity is highly dependent of the on the context in which is functioning for its creation and modulation. Though identity formation is not a totally conscious process there are instances where contextual factors may lead to conscious defining of identity issues. For example, racially prejudiced individuals are more motivated to make accurate racial categorization by enhancing the in-group characteristics and by avoiding out-group characteristics which defines clear boundaries between racial groups, than do non-prejudices individuals (Blascovich, Wyer, Swart, \& Kibler, 1997). The same can be said about the external environment such as the socio-political context in which these identities are embedded and function. 


\section{Identity learning}

Identity is not fixed at birth. No one is born with an identity. Though arguably there is biological evidence to explain some characteristics in sex identity and inheritable identities (Hauskeller, Sturdy, \& Tutton 2013; Imperato-McGinley, Lawrence, 2007; Peterson, Gautier, Sturla, 1979; Pol, et al., 2006) identities like ethnic and religious identities do not have any empirical basis at birth. Identity is learnt through experience.

Process of learning is a well-studied area in psychology. Learning can be defined as acquisition of knowledge or skills through study, experience, or being taught. Though there are many theories of learning, social learning theory suits best for our purpose in understanding how identity is learnt and reinforced in our memory for us to become the image that we are.

Social learning theory proposes that people learn through observing others' behavior, attitudes, and outcomes of those behaviors.

Children observe the people around them behaving in various ways. This learning process is illustrated in the famous Bobo doll experiment of Bandura (Bandura, 1961). Children are surrounded by models; this includes parents within the family, characters on children's TV, friends within their peer group and teachers at school. They observe these models' behavior in the society. These models provide them with ample behavior and attitudes that are prevalent in the society.

Children pay attention to some of these models whom they regard significant and and encode their behavior. Later they may imitate the behavior they have observed in these models. The child is more likely to imitate people who are perceived to be similar to itself and are probably in the same group to which the child belongs.

The people in the immediate surrounding of the child will respond to this new behavior it imitates with either reinforcement or punishment. If a child is rewarded for the new behavior, the child is likely to continue performing that behavior. The in-group behaviors are likely to be rewarded hence the child learns and imitate the in-group behaviors.

According to social learning theory a child observes the response to the model's behavior from others, when deciding whether or not to copy the model's actions. This helps the child to identity and emulate a model that possess qualities seen as rewarding. Children will have a number of models with whom they identify. Identification occurs with a model is not limited to adopting observed behaviors, it also involves adopting values, beliefs and attitudes of the person with whom the child is identifying.

A child's identity development involves a number of behaviors, values, beliefs and attitudes being adopted through the process of identification with models. Albert Bandura stated "Most human behavior is learned observationally through modeling: from observing others, one forms an idea of how new behaviors are performed, and on later occasions this coded information serves as a guide for action." According to social learning theory human behavior is molded by continuous reciprocal interaction between cognitive, behavioral, and environmental influences.

Social learning theory is considered as a bridge between the behavioral theory and the cognitive theory of learning (Bandura, 1971). Behavioral learning theory is a basic reflexive pattern like the spinal reflex arch without involvement of cognition. Behavioral theory of learning assumes that a learner is essentially passive, responding to environmental stimuli. Mental process involved in the mediation between the stimulus and response is not considered significant in this theory of learning. However, according to the behavior theory of learning behavior can be modified by positive and negative reinforcement.

Behavioral learning theory is based on reflexive response to external stimulus. This response can have two types of conditioning. Classical conditioning is a reflexive or automatic type of learning in which a stimulus acquires the capacity to evoke a response that was originally evoked by another stimulus. In operant conditioning a behavior is modified depending on the reward or punishment that is associated with the behavior. Behavioral learning theory provides a mechanistic type of basis for our 'identity learning' which is not very supportive of performativity of identity.

The cognitive theory of learning emphasizes on the mental processes involved in learning. These processes are influenced by internal and external factors in order to produce learning in individuals. The cognitive processes that can influence learning are: observing, categorizing, and forming generalizations about our environment.

Bandura has proposed four cognitive meditational processes that are involved in social learning theory. They are attention, retention, motoric reproduction and reinforcement and motivation. We observe many behaviors in our day to day life. But all don't grab our attention. We pay attention to behaviors that 
are worthy of imitation. We do not remember all the behaviors we see; only some we retain. Memory of a behavior is important for it to be performed later by the observer. Once a behavior is retained, it needs to be performed. All retained behaviors may not be performable. Motivation to perform a behavior depends on the rewards and punishment that follow a behavior. If a behavior is rewarded then the behavior will be more likely to be imitated by the observer (Bandura, 1971).

The learning processes discussed thus far may well explain the basis of how we learn our identity characteristics. This process of 'identity learning' starts very early in life and continues to be refined and redefined throughout life.

\section{Neuronal circuits and neuroplasticity}

The brain is composed of 100's of billions of inter connected neurons. These neurons through their interconnections form neuronal circuits or networks. These neuronal circuits, neuro transmitters and other chemical substances involved in the neuronal activities form the base of our memory and behavior (Cooper, 2005; Ochsner \& Lieberman, 2001).

How the brain mediates social processes and behavior has become a scientific research area shedding light into the neuronal mechanisms involved in social behavior. This evolving new specialty the social neuroscience, examines a wide range of research topics including social interactions, empathy, morality, and social affiliations.

New functional neuro imaging modalities like functional magnetic resonance imaging (fMRI), positron emission tomography (PET), electroencephalography (EEG), magnetoencephalography (MEG), near infrared spectroscopy (NIRS), and transcranial magnetic stimulation (TMS) are being used to analyses the neuronal networks involved in social interactions. (Shibasaki, 2008).

Early description of neuronal networks can be found in the works of Herbert Spencer, Theodor Meynert, William James and Sigmund Freud. However, it was Donald O. Hebb a Canadian psychologist who first described how these neuronal networks could be involved in learning. Hebb proposed that neurons undergo adaptive changes during the learning process through a basic mechanism called synaptic plasticity, where the synaptic efficacy increases due to repeated stimulation from the presynaptic cell. (Milner, 1993)

The work of Eric Kandel has provided evidence for the involvement of Hebbian learning mechanisms at synapses. Eric Kandel has demonstrated some of the basic molecular mechanisms underlying learning and memory in animals. His research has demonstrated the fundamental ways that nerve cells alter their response to chemical signals to produce coordinated changes in behavior. This work is central to understanding of memory (Bailey, Kandel, \& Harris, 2015).

It is well established that the learning and memory involve much more complex neuronal network than initially suggested by Hebb. In addition to neurons, chemical mediators are also known to play an important role in the modulation of neuronal activity. Neuronal network has complex interconnections of stimulatory and inhibitory activity.

Functional neuro imaging has enabled us to learn about the regions in brain that are involved in various process of learning and memory. Though these areas appear to be fixed these areas are highly malleable to training. In addition, new pathways could be created to take over the functions of a particular area when it is damaged. This adoptability of the brain is known as neuroplasticity. Neuroplasticity is made possible by new nerve connections and changes in the chemical mediators in the brain. (Campos, et al., 2016).

Neural circuits are the pathways which determine our actions and behaviors. Frequently used pathways become 'wired together and they fire together'. Though there are neuronal connections at birth there are no predetermined pathways at birth that determines our behavior and other characteristics. Neural pathways area created through our learning. Neuroplasticity shows us that the created pathway also could be changed through learning and training. (Telesford, Ashourvan, \& Wymbs, 2017). With the increasing understanding of the neuronal connections, brain plasticity research and the use of new imaging modalities it will be possible to map out the neuronal connections that govern dynamics of identity formation.

\section{Mind and performance}

Our mind has powerful influence and control over our performances. To illustrate this, we could turn to Sigmund Freud. Freud proposed that our mind functions in 3 levels. Conscious mind, subconscious mind and unconscious mind. Only about $10 \%$ of the minds work is made up of conscious 
thought. Conscious mind is what makes us aware of what we are doing instantly. Conscious mind does not depend on memory. It receives in formation, analyses them and make decisions.

The subconscious mind is the storage point for any recent memories needed for quick recall, it also holds current information that we use every day such as, behavior patterns, habits, and feelings. Subconscious mind forms $50-60 \%$ of the substrate of our mind

The unconscious mind is constituted by our old mummeries and past experiences. These could be memories repressed by trauma and forgotten events. These memories and experiences forms our beliefs, habits, and behaviors. Unconscious mind forms $30-40 \%$ of our mind.

Our mind acts as the store house of our identity script. Whereas, the psychic apparatus which is composed of id, ego and superego function as the regulator of our performance.

\section{Performativity of identity}

Ethnic identity is a discursive socio-cultural construct. The ethnic identity that is borne by the body is scripted through the history. The script precedes the performing body. Body assumes socio-cultural significance by performing the identity. In his writings French philosopher Michel Foucault rejected the view of a person having an inner and fixed 'essence' that is the person's identity. He identified the self as being defined by a continuing discourse in a shifting communication of oneself to others. Foucault says that the idea of agency in the social sciences "places its own point of origin of all historicity - which in short leads to a transcendental consciousness". Instead what is required according to Foucault is "not a theory of the knowing subject but rather a theory of discursive practice" (Foucault, 1970; Redman, 2000).

Idea of performativity is employed by Judith Butler in her writings (Butler, 1990). In the first chapter of Gender Trouble she quotes Nietzsche from Genealogy of Morals "There is no 'being' behind doing, acting, becoming: 'the doer' is merely a fiction impose on the doing- the doing itself is everything" (Nietzsche, 1887, p. 29). She takes this to prove her stand by saying "there is no gender identity behind the expression of gender; that identity is performatively constituted by the very 'expression' that are said to be its results" (Butler, 1990, p. 25).

Performativity is a series of effects resulting from our utterance/performance. This effect is continuously being produced and reproduced and reinforced. Our cultural identity/ethnic identity has various constituents. The way we talk, the way we eat, walk, interact with people all have our identity marks or rather all contribute our identity frame. These elements continuously reinforce our identity. All these elements have formative value in our identity formation.

Though our actions and behavior play a significant role in our identity formation, language forms the essential foundation in understanding and interacting these elements at the mental processing. There is no identity formation apart from language. The interactionist literature on identity identifies language as a main ingredient in constructing, articulating, negotiating and communicating ideas of identity (McAdams, 1995).

The ideas of Ethnic/cultural identity are mainly transmitted by media. This enables the out-group members to understand the ingredients of a particular identity formulation. This transmission occurs in the form of text. The scripted text of an identity already exists before the performer is known. In this manner identity can be fortified and modified depending on the socio-political context.

The characteristics that constitute the identity is learnt from childhood. The in-group characteristics are learnt on the basis of operant conditioning. When a child displays and in-group character it is positively reinforced. When a child displays a characteristic of out-group it is negatively reinforced. As long as the child learns and displays in-group characteristics it is positively reinforced and encouraged, this will ensure easy identification with in-group, where the child will be comfortable and feel secure. When the child displays out-group characteristics, the negative effects produced will lead the child to void those characteristics, in order to be in the group and feel secure. These positive and negative reinforcement could be regarded as what Butler as described as regulatory ideals following Foucault (Butler, 1993) or Haraway (1991) describes as regulatory fictions.

The regulatory ideals can function at two levels one is from within and the other is from without. This interaction will lead to differing mixture of characteristics to manifest to different degrees allowing an individual to assume individuality within the in-group. Some group identity characteristics are deeply rooted and resist change (Ahmed, 2016). The characteristics learnt and modulated are well ingrained in the neuronal network as they are used often. These pathways created in the neuronal network become least resistant and easily accessible pathways. This ensures that these pathways are used without volition. Functional neuro imaging has shown promise in mapping areas of brain that control behavioral activities. In 
the future with further development in the field of social neuroscience it will be possible to map brain areas that are involved in the control of identity characteristics.

\section{Conclusion}

Genetic studies have shown that certain sexual characteristics, morphological characteristics and some biological system characteristics are inheritable. This leaves nurture to be the most important determinant of identity characteristics in human beings. Scientifically proven learning theories afford good evidence to suggest that the identity characteristics are learnt form the environment. Recent evidence from neuro-science and functional neuro-imaging has made it possible to study how memory is formed and stored in neuronal network which forms the memory base for our performance. These development in scientific fields will pave way for expansion of multi-disciplinary research in identity formation.

The identity does not come from within. It is not in the substance of the performer. But the social learning creates a biological network which ultimately determines the performance of identity. The performativity of identity ensures the establishment of the identity of the performer. Identity is a performance of an existing script that is internalized in the neuronal network through the process of learning and regulated by psychological mechanisms.

\section{Reference}

Ahmed, M. (2016). Ethnicity, identity and group vitality: A study of Burushos of Srinagar. Journal of Ethnic and Cultural Studies, (3)1, 1-10.

Bailey, C. H., Kandel, E. R., \& Harris, K. M. (2015). Structural components of synaptic plasticity and memory consolidation. Cold Spring Harbor Perspectives in Biology, 7(7). doi:10.1101/cshperspect.a021758.

Bandura, A. (1971). Social learning theory. New York: General Learning Press.

Bandura, A., Ross, D., \& Ross, S.A. (1961). Transmission of aggression through imitation of aggressive models. Journal of Abnormal and Social Psychology, 63, 575-582.

Baumeister, R.F. (1999). The self in social psychology. Philadelphia, PA: Psychology Press at Taylor \& Francis.

Beck, U. (1992). Risk society: Towards a new modernity. London: Sage Publication.

Blascovich, J., Wyer, N., Swart, L., \& Kibler, J. (1997). Racism and racial categorization. Journal of Personality and Social Psychology, (72)6, 1364-1372.

Bloche, M. G. (2004). Race-based therapeutics. New England Journal of Medicine. 351, 2035-2037.

Bracher, M. (1994). On the psychological and social function of language: Lacan's Theory of the Four Discourses. In Bracher, M., Alcorn, M. W., Corthell, R. J., \& Massardier-Kenney, F. (Eds.), Lacanian Theory of Discourse. (pp 107 -128). New York, NY: University Press.

Brewer, M. (1991) The social self - On being the same and different at the same time. Personality and Social Psychology Bulletin, 17, 475-482.

Brewer, M. (2001) Ingroup identification and intergroup conflict: When does ingroup love become outgroup hate? In Ashmore, R. D., Jussim, L., \& Wilderet, D. (Eds.), Rutgers series on self and social identity; Social identity, intergroup conflict, and conflict reduction (pp. 17-41). New York: Oxford University Press.

Butler, J. (1990). Gender trouble: Feminism and the subversion of identity. New York: Routledge.

Butler, J. (1993). Bodies that matter: On the discursive limits of "sex". New York: Routledge.

Byker, E. J., \& Marquardt, S. K. (2016). Using critical cosmopolitanism to globally situate: Multicultural education in teacher preparation courses. Journal of Social Studies Education Research, 7(2), 3050.

Campos, C., Santos, S., Gagen, E., Machado, S., Rocha, S., Kurtz, M. M.,\& Rocha, N. B. (2016). Neuroplastic changes following social cognition training in schizophrenia: A systematic review. Neuropsychology Review, 26(3), 310-328.

Cooper, S. J. (2005). Donald O. Hebb's synapse and learning rule: A history and commentary. Neurosciences \& Biobehavioral Review, 28(8), 851-74.

Damgacı, F. K., \& Aydın, H. (2013). Türkiye'deki Eğitim Fakültelerinde Görev Yapan Akademisyenlerin Çokkültürlü Eğitime İlişkin Görüşleri. Dicle Üniversitesi Ziya Gökalp Eğitim Fakültesi Dergisi, 21(2), 314-331.

Foucault, M. (1970). The order of things. p XIV. London: Navistock. 
Frith. C. (2008). Social cognition. Philosophical Transactions of the Royal Society B: Biological Sciences, 363(1499), 2033-2039.

Giddens, A. (1991). Modernity and self-identity: Self and society in the Late Modern Age. Stanford, CA: Stanford University Press.

Goffman, E. (1959). The presentation of self in everyday life. New York, NY: Doubleday.

Haraway, D. (1991). Situated knowledges: The science question in feminism and the privilege of partial perspective. In D. Haraway (Ed.), Simian, cyborgs and women: the reinvention of nature. (pp 183202) New York: Routledge.

Hauskeller, C., Sturdy, S., \& Tutton, R. (2013). Genetics and the sociology of identity. Sociology, 47(5), 875-886.

Imperato-McGinley, J., Peterson, R. E., Gautier, T., \& Sturla, E. (1979). Androgens and the evolution of male-gender identity among male pseudohermaphrodites with 5alpha-reductase deficiency. New England Journal of Medicine, 300(22), 1233-1237.

Kiang, L. (2014). Ethnicity and ethnic identity in context. Human Development, 57, 213-221.

Lawrence, A. A. (2007). A critique of the Brain-Sex Theory of Transsexualism [Web log post]. Retrieved from http://www.annelawrence.com/brain-sex_critique.html, Accessed 23 October 2017.

McAdams, D. (1995). What do we know when we know a person? Journal of Personality, 63, 365-396.

Milner, P. M. (1993). The mind and Donald O. Hebb. Scientific American, 268(1), 124-129.

Mountain, J. L, \& Risch, N. (2004). Assessing genetic contributions to phenotypic differences among 'racial' and 'ethnic' groups. Nature Genetics, 36 (Suppl 11), S48-S53.

Nietzsche, F. (1887). On the Genealogy of Morals (Zur Genealogie der Moral), trans. (1996) Douglas Smith, Oxford: Oxford University Press.

Ochsner, K. N., \& Lieberman. (2001). The emergence of social cognitive neuroscience. American Psychologist, 56(9), 717-734.

Owens.T. J., Robinson, D. T, \& Smith-Lovin, L. (2010). Three faces of identity. Annual Review of Sociology, 36, 477-499.

Oyerman, D., Elmore, K., \& Smit, G. (2012). Self, self-concept, and identity. In M. R. Leary \& J. P. Tangney (Eds.), Handbook of self and identity (2nd ed.) (p. 76). New York, NY: Guilford Press,

Oyserman, D. (2007). Social identity and self-regulation. In A. W. Kruglanski \& E. T. Higgins (Eds.), Social psychology: Handbook of basic principle. (2nd ed.) (pp. 432-453). New York, NY: Guilford Press.

Pol. H., Cohen-Kettenis, P.T., Van Haren, N. E., Peper, J. S., Brans, R. G., \& Cahn, W. (2006). Changing your sex changes your brain: Influences of testosterone and estrogen on adult human brain structure. European Journal of Endocrinology, 155, 107-114.

Ramarajan. L. (2014). Past, present and future research on multiple identities: Toward an intrapersonal network approach. The Academy of Management Annals, 8(1), 589-659.

Redman, P. (2000). Introduction. In P. du Gay, J. Evans, \& P. Redman (Eds.), Identity: a reader (pp. 110) London: Sage.

Shibasaki, H. (2008). Human brain mapping: hemodynamic response and electrophysiology. Clinical Neurophysiology, 119(4), 731-743.

Stapel, D. A., \& Koomen, W. (2001). I, we, and the effects of others on me: How self-construal level moderates' social comparison effects. Journal of Personality and Social Psychology, 80, 766-781.

Stryker, S. (1980). Symbolic interactionism: A social structural version. Menlo Park, CA: BenjaminCummings.

Swann, W. B., Gómez A, Seyle, D. C, Morales, J. F., \& Huici, C. (2009). Identity fusion: The interplay of personal and social identities in extreme group behavior. Journal of Personality and Social Psychology, 96(5), 995-1011.

Tajfel, H., \& Turner, J. (2004). The Social Identity Theory of Intergroup Behavior. In J. T. Jost \& J. Sidanius (Eds.), Key readings in social psychology. Political psychology: Key readings, (pp. 276293) New York: Psychology Press.

Tarman, B. (2017). Editorial: The Future of Social Sciences. Research in Social Sciences and Technology, 2(2). Retrieved from http://ressat.org/index.php/ressat/article/view/329

Telesford, Q. K, Ashourvan, A., \& Wymbs, N. F. (2017). Cohesive network reconfiguration accompanies extended training. Human Brain Mapping, 38(9), 4744-4759.

Ugurlu, O. (2014). Identity formation and community organization among Kurdish diaspora in London1. Journal of Ethnic and Cultural Studies, 1(1), 22-34. 
Yiğit, M. F., \& Tarman, B. (2016). How do different ethnicities approach to the education system and differences in Turkey? Italian Sociological Review, (6)3, 339-353. 